\title{
CORRECTION
}

\section{Correction to: Dual-stage artificial neural network (ANN) model for sequential LBMM- $\mu$ EDM-based micro-drilling}

\author{
Wazed Ibne Noor ${ }^{1} \cdot$ Tanveer Saleh $^{1} \cdot$ Mir Akmam Noor Rashid ${ }^{1}$. Azhar Mohd Ibrahim ${ }^{2}$. \\ Mohamed Sultan Mohamed $\mathrm{Ali}^{3}$
}

Published online: 21 September 2021

(C) Springer-Verlag London Ltd., part of Springer Nature 2021

\section{Correction to: The International Journal of Advanced}

Manufacturing Technology

https://doi.org/10.1007/s00170-021-07910-w

The original article contained a mistake. Equation 3 in the article was miswritten. The corrected version is given in the following table.

\begin{tabular}{ll}
\hline Current version & Corrected version \\
$y_{i_{R M S E}}=\frac{\sum_{j=1}^{N}\left(y_{i_{\text {acctual }}}-y_{i_{\text {prredicted }}}\right)^{2}}{N}$ & $\mathrm{y}_{\mathrm{i}_{\text {RMSE }}}=\sqrt{\frac{\sum_{\mathrm{j}=1}^{\mathrm{N}}\left(\mathrm{y}_{\mathrm{i}_{\mathrm{j} a c t u a l}}-\mathrm{y}_{\mathrm{i}_{\text {predicted }}}\right)^{2}}{\mathrm{~N}}}$ \\
$(3)$ & $(3)$ \\
\hline
\end{tabular}

The original article has been corrected.

Publisher's Note Springer Nature remains neutral with regard to jurisdictional claims in published maps and institutional affiliations.

The original article can be found online at https://doi.org/10.1007/ s00170-021-07910-w.

Tanveer Saleh

tanveers@iium.edu.my

1 Autonomous Systems and Robotics Research Unit (ASRRU), Department of Mechatronics Engineering, International Islamic University Malaysia, 53100 Kuala Lumpur, Malaysia

2 Department of Mechatronics Engineering, International Islamic University Malaysia, 53100 Kuala Lumpur, Malaysia

3 School of Electrical Engineering, Universiti Teknologi Malaysia, UTM, 81310 Johor Bahru, Johor, Malaysia 